\title{
Trajectories of Stroke Care in Ontario: Which Path to Best Care?
}

\author{
Ruth E. Hall, Diana Sondergaard, Walter P. Wodchis, Jiming Fang, \\ Prosanta Mondal, Mark T. Bayley
}

\begin{abstract}
Background: Few studies have tracked stroke survivors through transitions across the health system and identified the most common trajectories and quality of care received. The objectives of our study were to examine the trajectories that incident stroke patients experience and to quantify the extent to which their care adhered to the best practices for stroke care. Methods: A population-based cohort of first-ever stroke/transient ischemic attack (TIA) patients from the 2012/13 Ontario Stroke Audit was linked to administrative databases using an encrypted health card number to identify dominant trajectories $(N=12,362)$. All trajectories began in the emergency department (ED) and were defined by the transitions that followed immediately after the ED. Quality indicators were calculated to quantify best practice adherence within trajectories. Results: Six trajectories of stroke care were identified with significant variability in patient characteristics and quality of care received. Almost two-thirds (64.5\%) required hospital admission. Trajectories that only involved the ED had the lowest rates of brain and carotid artery imaging ( 91.5 and $44.2 \%$, respectively). Less than $20 \%$ of patients in trajectories involving hospital admissions received care on a stroke unit. The trajectory involving inpatient rehabilitation received suboptimal secondary prevention measures. Conclusions: There are six main trajectories stroke patients follow, and adherence to best practices varies by trajectory. Trajectories resulting in patients being transitioned to home care following ED management only are least likely and those including inpatient rehabilitation are most likely to receive stroke best practices. Increased time in facility-based care results in greater access to best practices. Stroke patients receiving only ED care require closer follow-up by stroke specialists.
\end{abstract}

RÉSUMÉ: Trajectoires de soins cliniques de l'AVC en Ontario : quelle est la plus conforme aux pratiques exemplaires ? Contexte: Peu d'études ont effectué un suivi des personne survivantes d'un AVC dans l'ensemble du système de santé. Peu nombreuses sont aussi celles ayant déterminé les trajectoires de soins cliniques qui leur ont été alors prodigués ainsi que leur qualité. Notre étude comporte ainsi deux objectifs : d'une part, examiner les trajectoires de soins cliniques offerts aux patients victimes d'un AVC; d'autre part, déterminer dans quelle mesure ces soins sont conformes aux pratiques exemplaires en matière de soins de l'AVC. Méthodes: Une cohorte représentative de la population a inclus des patients victimes (pour la première fois) d'un AVC ou d'un accident ischémique transitoire (AIT) et choisis à partir du Ontario Stroke Audit (2012-2013). Cette cohorte a été couplée à des bases de données administratives au moyen d'un numéro d'assurance santé encodé afin d'identifier les principales trajectoires $(\mathrm{N}=12362)$. Toutes les trajectoires de soins cliniques débutent au moment de l'admission dans un service des urgences; elles ont été définies par l'ensemble des interventions consécutives à cette admission. Des indicateurs de qualité ont été utilisés afin de mesurer, par rapport à chaque trajectoire de soins cliniques, leur conformité aux pratiques exemplaires. Résultats: En matière de soins de l'AVC, six trajectoires ont été identifiées. On a ainsi pu observer une variabilité importante en ce qui regarde les caractéristiques des patients et la qualité des soins prodigués. Près des deux-tiers (64.5\%) d'entre eux a été hospitalisé. De plus, les trajectoires limitées aux seuls services des urgences ont donné à voir les plus bas taux d'imagerie du cerveau et de l'artère carotide (respectivement 91,5 et 44,2 \%). Moins de $20 \%$ des patients dont les trajectoires ont sous-tendu une hospitalisation ont reçu des soins dans un service spécialisé de l'AVC. La trajectoire supposant la réadaptation de patients hospitalisés s'est aussi distinguée par des mesures de prévention secondaire sous-optimales. Conclusions: Six trajectoires principales de soins cliniques ont été identifiées parmi un groupe de patients victimes d'un AVC. La conformité aux pratiques exemplaires a varié d'une trajectoire à l'autre. Les trajectoires ayant inclus des soins à domicile à la suite de traitements reçus uniquement dans un service des urgences demeurent moins probables. En outre, les patients hospitalisés à qui l'on a offert des services de réadaptation sont les plus susceptibles de recevoir des soins conformes aux pratiques exemplaires. Fait à noter, un séjour prolongé dans un établissement de santé s'est traduit par un meilleur accès à des soins conformes aux pratiques exemplaires. Enfin, les patients victimes d'un AVC n'ayant reçu que des soins dans un service des urgences ont nécessité un suivi plus étroit de spécialistes de l'AVC.

Keywords: Acute stroke, TIA, stroke registry, quality of care, clinical practice guidelines

doi:10.1017/cjn.2016.440

Can J Neurol Sci. 2017; 44: 261-266

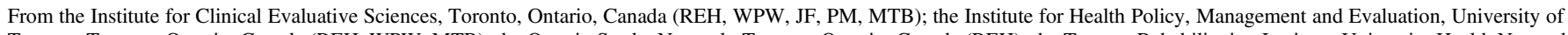

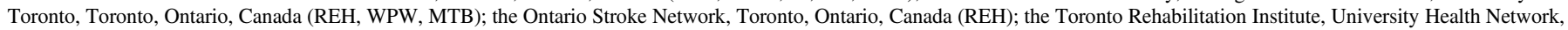

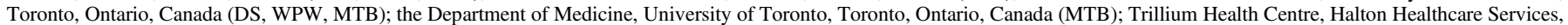
Toronto, Ontario, Canada (DS).

Received November 26, 2015. Final Revisions Submitted June 20, 2016. Date of Acceptance July 18, 2016

Correspondence to: Ruth Hall, Institute for Clinical Evaluative Sciences, 2075 Bayview Avenue, G106, Toronto, Ontario, Canada M4N 3M5. Email: ruth@ices.on.ca. 


\section{INTRODUCTION}

Organized stroke care results in reduced death and disability, but it is very complex. ${ }^{1}$ There is abundant literature regarding the quality of stroke care within an individual setting or transitions between two sectors (e.g., acute to inpatient rehabilitation). ${ }^{2-12}$ However, few studies have tracked stroke survivors across the entire continuum to understand the quality of care they received and their outcomes. ${ }^{13-15}$ This is a significant gap in our knowledge, as stroke patients take many variable paths or trajectories through the healthcare system. The Canadian Stroke Strategy has identified a Model for Transitions of Stroke Care and corresponding best practices for each sector, including: acute care, inpatient and outpatient rehabilitation, stroke secondary prevention clinics and primary care follow-up. ${ }^{16}$ However, the proportion of stroke patients following the various trajectories and the quality of care are not known.

The reason for this lack of evaluation may be that very few health systems have the capacity to follow patients across the entire continuum of stroke care. ${ }^{12,17-20}$ There is a dearth of studies that provide real-world knowledge of the care pathways for stroke patients based on comprehensive observational data to highlight where to focus quality improvement and stroke system planning.

The objectives of our study, therefore, were: (1) to characterize the first-year care trajectories and outcomes for first-ever acute stroke/transient ischemic attack (TIA) patients; (2) to describe the patient demographic factors (i.e., age, sex and stroke severity) associated with each trajectory; (3) to measure adherence to available best practices guidelines (i.e., appropriate diagnostic testing, access to specialists and prescribing stroke-prevention medications); and (4) to identify the priority areas of the stroke system upon which to focus quality-improvement activities.

\section{Methods}

\section{Data Sources and Cohort Creation}

The Ontario Stroke Registry (OSR) (formerly known as the Registry of the Canadian Stroke Network, or RCSN) performs a population-based biennial audit of the patients seen at all acute care institutions in Ontario. The 2012/13 Ontario Stroke Audit (OSA) is a random sample of patients 18 years of age and older discharged from the emergency department (ED) or from an inpatient stay between 1 April 2012 and 31 March 2013, with a main problem/most responsible diagnosis of stroke or TIA among hospitals seeing at least 30 strokes/TIAs per year. If there was more than one stroke/TIA during the sampling period, only the first stroke/TIA event was included. ${ }^{21}$ Results were weighted using the reciprocal of the probability that the chart was selected to provide for population estimates. ${ }^{21}$

Chart abstraction was performed by trained research personnel, and if chart review confirmed a diagnosis of stroke or TIA, the event was included in the OSA. The OSA collects information on stroke type and severity, presenting symptoms and co-morbid conditions, and validation by duplicate chart abstraction has shown excellent agreement for key variables, including age, sex, stroke type and admission to hospital. ${ }^{22}$

The OSR is housed at the Institute for Clinical Evaluative Sciences (ICES), where it is linked to population-based administrative databases using unique encoded patient identifiers. Using an encrypted health card number, we excluded OSA patients who had had a stroke/TIA emergency department visit or hospitalization in the three years prior to the 2012/13 stroke event to identify first-ever stroke patients, leaving 12,362 patients to assign a trajectory. All trajectories began with an admission to the ED at 100 acute hospitals. A trajectory was classified by the first and/or second transition after ED care (e.g., home, home with home care, inpatient rehabilitation, complex continuing care or long-term care) using a unique encrypted health card number linked to several administrative databases and analyzed at the ICES (see supplementary material, Appendix 1).

\section{Data Analyses}

Results were weighted using the reciprocal of the probability that the audited chart was selected to provide for population estimates. $^{21}$ This resulted in a cohort of 18,871 first ever stroke/TIA patients. Adherence to best practices stroke care was calculated as the proportion of patients receiving best practices among all eligible patients in that trajectory expressed as a percentage. The acute phase process indicators calculated are included in the Ontario Stroke Network's stroke report card $^{23}$ and include: dysphagia screening, neuro- and carotid imaging, thrombolytic therapy (tissue plasminogen activator [tPA]), admission to a stroke unit and referral to a secondary prevention services. Post-acute best practices indicators were selected based on data availability in Ontario. We excluded patients who died during the follow-up for medication adherence only. Patients were followed for up to 365 days after the index event.

\section{Results \\ Predominant Trajectories of Stroke Care in Ontario}

There are six predominant trajectories following a first-ever stroke/TIA in Ontario, and most (64.5\%) involve hospitalization. Four of the six trajectories transition to the community after an acute event. The most common trajectory of care $(26 \%)$ is transitioning to home from the ED (T1).

\section{Patient Characteristics (see Table 1)}

In the Table 1 most common trajectory (T1), most patients experience a TIA (82.8\%), are younger (69.5 years), male (50.9\%), have fewer co-morbidities $(5.4 \%$ with a Charlson comorbidity index of 3 or more) and were living independently prior to the stroke $(84.5 \%)$. In contrast, those transitioned to home care from the ED (T2) were over a decade older (median = 80.7 years), more likely to be female $(57.3 \%)$ and less independent $(53.9 \%)$.

Trajectories with transitions directly to home following an acute stroke (T1 and T3) had patients similar in age (69.5 vs. 68.3 years) and independence ( 84.5 vs. $87.6 \%)$, but were more likely males, with fewer comorbidities (5.4 vs. $11.0 \%$, with a Charlson comorbidity index $\geq 3$ ). However, T3 (admitted) patients had more severe strokes ( 93.8 vs. $82.1 \%$, considered mild).

Patients in trajectories including home care (T2 and T4) were older, more likely female and had more co-morbidities, but admitted patients (T4) were more independent (64.0 vs. 53.9\%) and experienced more severe strokes (70.6 vs. $85.2 \%$ mild) compared to those not admitted. 
Table 1: Patient Characteristics in Six Stroke Care Trajectories

\begin{tabular}{|c|c|c|c|c|c|c|}
\hline & $\begin{array}{c}\text { ED to } \\
\text { home (T1) }\end{array}$ & $\begin{array}{l}\text { ED to home } \\
\text { with home care } \\
\text { (T2) }\end{array}$ & $\begin{array}{c}\text { ED: } \\
\text { inpatient to } \\
\text { home (T3) }\end{array}$ & $\begin{array}{l}\text { ED: inpatient to } \\
\text { home with home } \\
\text { care (T4) }\end{array}$ & $\begin{array}{l}\text { ED: inpatient to } \\
\text { inpatient } \\
\text { rehabilitation (T5) }\end{array}$ & $\begin{array}{c}\text { ED: inpatient to complex } \\
\text { continuing care/long-term } \\
\text { care (T6) }\end{array}$ \\
\hline$N=18,871($ FY 2012/13) & 4,931 & 1,767 & 3,449 & 3,884 & 3,331 & 1,508 \\
\hline$\%$ female & 49.1 & 57.3 & 38.8 & 53.9 & 46.5 & 58.7 \\
\hline Median age & 69.5 & 80.7 & 68.3 & 78.1 & 73.5 & 81.4 \\
\hline (25th and 75th percentile) & $(59.5-78.6)$ & $(72.6-86.7)$ & $(58.3-77.3)$ & $(67.4-85.3)$ & $(62.4-81.7)$ & $(72.2-87.1)$ \\
\hline \multicolumn{7}{|l|}{ Stroke type } \\
\hline TIA & 82.8 & 78.2 & 34.9 & 23.2 & 1.9 & 6.9 \\
\hline Ischemic & 16.7 & 21.1 & 59.0 & 69.2 & 86.8 & 79.5 \\
\hline Haemorrhagic & 0.5 & 0.7 & 6.1 & 7.6 & 11.3 & 13.6 \\
\hline UTD & 0.48 & 0.52 & 0.34 & 0.28 & 0.21 & 0.38 \\
\hline$\%$ independent prior to stroke & 84.5 & 53.9 & 87.6 & 64.0 & 76.4 & 41.2 \\
\hline Charlson score of 3 or more & 9.9 & 10.3 & 14.1 & 32.5 & 19.2 & 13.9 \\
\hline $\begin{array}{l}\text { \% living in a long-term care, home or } \\
\text { retirement residence at time of } \\
\text { stroke/TIA }\end{array}$ & 2.7 & 6.0 & 1.7 & 2.5 & 0.8 & 26.5 \\
\hline \multicolumn{7}{|l|}{ Stroke severity* } \\
\hline$\%$ mild & 93.8 & 85.2 & 82.1 & 70.6 & 57.8 & 37.0 \\
\hline \multicolumn{7}{|l|}{ Disability at discharge } \\
\hline$\%$ mRS $0-2$ & 91.1 & 78.7 & 87.6 & 57.4 & 15.4 & 6.2 \\
\hline mRS 3 & 1.2 & 8.1 & 5.7 & 21.8 & 35.3 & 17.9 \\
\hline mRS 4-5 & 1.4 & 4.4 & 4.6 & 16.8 & 43.4 & 72.0 \\
\hline $\mathrm{UTD}^{\dagger}$ & 6.4 & 8.8 & 2.2 & 3.9 & 5.9 & 3.9 \\
\hline
\end{tabular}

*Measured on the Canadian Neurological Scale 8 or higher.

$\mathrm{mRS}=$ modified Rankin score.

${ }^{\dagger}$ Not enough information in the chart for abstractors to be able to calculate.

Trajectory five (transition to inpatient rehabilitation) had the second youngest stroke/TIA patients (median age $=73.5$ years). T5 also had the highest prevalence of patients who had been independent in terms of performing the activities of daily living prior to their stroke and after their discharge home without supports (T1 and T3) (76.4\%), but they experienced more severe strokes (only $57.8 \%$, mild strokes) compared to patients discharged home with or without supports and a high proportion of patients with a modified Rankin score $>2(84.6 \%)$ at the time of discharge from the acute hospital.

The least common trajectory (T6) involved direct transition to long-term care (LTC) or complex continuing care (CCC) facilities. In fact, $26.5 \%$ resided in an LTC-type residence prior to their index stroke/TIA. This group was the oldest (median age $=$ 81.4 years), had the highest proportion of women $(58.7 \%)$ and had the lowest proportion of patients considered to be independent (41.2\%). Less than half of T6 patients experienced a mild stroke $(37.0 \%)$, and $93.8 \%$ had a discharge modified Rankin score $>2$.

\section{Adherence to Acute Stroke Care Best Practices}

Trajectory five had the highest proportion of patients receiving best practices stroke care, with the exception of referrals to a secondary stroke prevention clinic and warfarin adherence (Table 2). This trajectory also had the highest prevalence of tPA delivery (15.6\%). T4 had the lowest proportion receiving tPA despite having a greater proportion of ischemic stroke patients as compared to T3. Among the trajectories that included hospitalization, T3 (transition to home) had the lowest proportion of patients cared for on a stroke unit (9.2\%) with swallowing assessed $(47.4 \%)$ but had the highest percentage referred to a secondary stroke prevention clinic (65.8\%) among patients admitted to hospital. Trajectory T6 (transition to CCC or LTC) had the second highest rate of patients treated on a stroke unit (16.7\%). Patients discharged home (T3 and T4) had the lowest proportion of patients treated on a stroke unit.

Trajectories without an inpatient stay (T1 and T2) had the lowest rates of brain and carotid artery imaging (44.2 and 38.8\%) and the highest secondary prevention clinic referrals (81.4 and $73.4 \%$, respectively) compared to trajectories with an inpatient stay for acute stroke management. These patients also had the lowest 30-day family physician visit rate (70.0 and 69.9\%) of all the trajectories but the highest rate of seeing both a family physician and specialist (54.6 and 49.1\%). Furthermore, the median time to see a specialist was shorter for trajectories without an inpatient stay compared to hospitalized patients transitioned to the community: 5.1 versus 7.4 days (T1 vs. T3) and 5.6 versus 6.9 days (T2 vs. T4). The median time to specialist visit was shortest for T5 (acute + inpatient rehabilitation) at 2.4 days, followed by T6 at 5.2 days. Trajectories T2 and T4 (transitions to 
Table 2: Adherence to Best Practices among Six Stroke Care Trajectories

\begin{tabular}{|c|c|c|c|c|c|c|}
\hline Trajectory & $\begin{array}{l}\text { ED to home } \\
(\mathrm{T} 1) \\
(n=4,931)\end{array}$ & $\begin{array}{l}\text { ED to home } \\
\text { with home care } \\
(\mathrm{T} 2)(n=1,767)\end{array}$ & $\begin{array}{l}\text { ED: inpatient } \\
\text { to home }(T 3) \\
(n=3,449)\end{array}$ & $\begin{array}{l}\text { ED: inpatient to } \\
\text { home with home } \\
\text { care (T4) } \\
(n=3,884)\end{array}$ & $\begin{array}{l}\text { ED: inpatient to } \\
\text { inpatient } \\
\text { rehabilitation (T5) } \\
\quad(n=3,331)\end{array}$ & $\begin{array}{l}\text { ED: inpatient to complex } \\
\text { continuing care/long-term } \\
\text { care (T6) }(n=1,508)\end{array}$ \\
\hline $\begin{array}{l}\% \text { receiving } \mathrm{CT} \text { within } 24 \mathrm{hr} \text { of hospital } \\
\text { arrival }\end{array}$ & 91.5 & 88.5 & 99.4 & 99.5 & 99.9 & 99.8 \\
\hline$\%$ stroke unit admission & NA & NA & 9.2 & 10.9 & 18.0 & 16.7 \\
\hline$\%$ receiving tPA & NA & 0 & 13.7 & 11.1 & 15.7 & 13.5 \\
\hline$\%$ carotid imaging booked or done & 44.2 & 38.8 & 86.4 & 79.2 & 83.8 & 69.4 \\
\hline$\%$ swallowing assessment & 0.8 & 1.5 & 47.4 & 59.3 & 76.7 & 81.9 \\
\hline$\%$ referred to secondary prevention clinic & 81.4 & 73.4 & 65.8 & 50.0 & 37.6 & 21.6 \\
\hline $\begin{array}{l}\% \text { patients with follow-up visit to family } \\
\text { physician within } 30 \text { days of index } \\
\text { stroke/TIA discharge }\left(C_{95 \%}\right)\end{array}$ & $\begin{array}{c}70.0 \% \\
(68.2-71.8)\end{array}$ & $\begin{array}{c}69.9 \% \\
(67.0-72.7)\end{array}$ & $\begin{array}{c}78.6 \% \\
(76.8-80.4)\end{array}$ & $\begin{array}{c}81.4 \% \\
(79.7-83.1)\end{array}$ & $\begin{array}{c}84.9 \% \\
(83.4-86.3)\end{array}$ & $\begin{array}{c}90.1 \% \\
(88.1-92.0)\end{array}$ \\
\hline $\begin{array}{l}\text { Median time ( } 25 \text { th and } 75 \text { th percentile) to } \\
\text { first family physician visit from index } \\
\text { event discharge }\end{array}$ & $6.5(2.5-13.6)$ & $6.9(2.8-14.8)$ & $6.2(279-12.5)$ & $6.3(2.3-13.1)$ & $1.0(1.0-2.7)$ & $1.9(1.0-6.8)$ \\
\hline $\begin{array}{l}\% \text { with specialist* and family physician } \\
\text { follow-up visit within } 30 \text { days of index } \\
\text { stroke/TIA discharge }\left(C_{95 \%}\right)\end{array}$ & $\begin{array}{c}54.6 \% \\
(52.7-56.5)\end{array}$ & $\begin{array}{c}49.1 \% \\
(46.0-52.2)\end{array}$ & $\begin{array}{c}45.0 \% \\
(42.7-47.2)\end{array}$ & $\begin{array}{c}41.3 \% \\
(39.1-43.4)\end{array}$ & $\begin{array}{c}40.5 \% \\
(38.5-42.6)\end{array}$ & $\begin{array}{c}28.8 \% \\
(25.8-31.7)\end{array}$ \\
\hline $\begin{array}{l}\text { Median time ( } 25 \text { th and } 75 \text { th percentile) to } \\
\text { first specialist* follow-up (days) }\end{array}$ & $5.1(1.9-11.0)$ & $5.6(2.0-12.2)$ & $7.4(2.4,15.5)$ & $6.9(2.0-15.7)$ & $2.4(1.0-9.8)$ & $5.2(1.0-12.5)$ \\
\hline \multicolumn{7}{|l|}{ Warfarin prescribed ${ }^{\ddagger}$} \\
\hline 90 days post-event & 48.6 & 54.7 & 52.3 & 54.2 & 49.0 & 38.9 \\
\hline One-year post-event & 52.7 & 60.6 & 56.8 & 61.1 & 56.6 & 51.3 \\
\hline
\end{tabular}

$C I_{95 \%}=95 \%$ confidence interval $\mathrm{CT}=$ computed tomography; $\mathrm{tPA}=$ tissue plasminogen activator.

*Specialist was defined as neurologist, neurosurgeon, internist, cardiologist or physiatrist.

${ }^{¥}$ Ischemic stroke/TIA patients with atrial fibrillation 65 years of age and older.

home care) had the highest use of warfarin at three months and one year following the stroke/TIA: $54.7,60.6 \%$ and $54.2,61.1 \%$, respectively.

\section{DiscuSSION}

This is the first population-based study to characterize adherence to best practices by care trajectory following first-ever stroke/TIA. We have found six health system care trajectories that first-onset stroke patients in Ontario follow. Two of the six trajectories do not include an inpatient stay and are predominantly TIA patients at high risk for a stroke. Each trajectory is associated with significant variability in terms of patient characteristics and adherence to identified best practices.

Not surprisingly, patients managed in the ED only had less severe strokes and fewer co-morbidities. In contrast, those discharged to long-term care (T6) were older, less independent prestroke and more disabled. It was noteworthy that those going to rehabilitation (T5) were younger, raising the possibility of ageism inpatient rehabilitation admission policies. Long-term care (T6) is resource-intensive, and it is possible that the longitudinal cost of care could be reduced if more received rehabilitation. Overall, a small percentage of first-ever stroke/TIA patients transition directly to inpatient rehabilitation: 17.7\% (T5). A 2009 analysis of stroke rehabilitation in Canada reported that inadequate access to resources that focus on rehabilitation has meant that admission to long-term care has remained largely unchanged. ${ }^{10}$
Patients transitioning to home care services (T2, T4) or to long-term care (T6) were older, more likely female, less likely independent prior to their stroke and had experienced a more severe stroke. Women have strokes at an older age, innately live longer than men and are less likely to have male caregivers to support them. The results of our study bolster the literature which shows that those aged over 80 have worse overall outcomes, including higher mortality rates and longer lengths of stay, and are less commonly discharged to their pre-stroke location. ${ }^{24,25}$

In terms of quality of care, among patients receiving ED-only management (T1 and T2), less than 50\% had carotid imaging, and $30 \%$ did not follow up with any physician within 30 days of the stroke/TIA. The median time to see a physician was six days. This suboptimal follow-up in T1 and T2 among those who had high rates of prescribed warfarin raises the concern that less frequent monitoring may contribute to the higher rates of ischemic stroke among atrial fibrillation patients newly prescribed warfarin. ${ }^{26}$

Among trajectories with an inpatient stay, less than $20 \%$ of patients received stroke unit care. Stroke units reduce death or institutionalization with the same magnitude of effect across all age groups. ${ }^{27}$ In trajectories where post-acute stroke patients were transitioned to the community (T1-T4), screening rates for dysphagia were the lowest, but this may be due to their shorter length of stay compared to T5 and T6. A more concerning possibility is that clinicians take a nihilistic approach to older people with fewer referrals to inpatient rehabilitation, less use of preventive medication and less access to follow-up care (T6). 
T5 and T6 have the lowest one-year warfarin adherence rates, suggesting that the need to ensure secondary prevention is conveyed better in the discharge care plans.

Our study has several limitations worth commenting on. Not all Ontario acute care hospitals were included in the 2012/13 OSA; therefore, the analysis does not provide a picture of all acute stroke care episodes and may overestimate the adherence to best practices by excluding hospitals that see less than 30 stroke/TIA cases a year. Subarachnoid haemorrhage stroke patients were not included. However, given that this stroke type represents less than $10 \%$ of stroke patients, it is unlikely to have impacted our results. Adherence to secondary stroke prevention medications was obtained from the Ontario Drug Benefits (ODB) database, limiting quantification of adherence to patients over age 65 years at the time of the acute stroke/TIA. Adherence to antiplatelet medications was not calculated, as aspirin is not covered nor tracked by the ODB program. Finally, our results were obtained within the context of an organized system of stroke care and may not be generalizable to other settings.

This study is based on recent stroke care, and many indicators of best practice care may have improved in the meantime. In a more current report on stroke care in Ontario, stroke unit care and carotid imaging among stroke/TIA patients improved, and provided insights into trajectories where further improvement is needed. ${ }^{28}$ During the period of our study, early supported discharge (ESD) was not available in the province of Ontario, and so it is not unexpected that transitions involving home care had a lower prevalence of many best practices that are part of ESD programs.

\section{CONCLUSIONS}

In conclusion, we have identified six main trajectories following a first-ever stroke/TIA. Significant variability in age, severity of stroke, presence of co-morbidities, pre-morbid functioning and quality of care exists across these trajectories. Our population-based observational study provides estimates of adherence to several best practices useful for stroke system planning in Ontario as well as for other countries/regions with a formalized stroke system. Future analysis with this cohort will examine which trajectories and elements of care are associated with the best one-year outcomes.

We also identified four areas for improvement in stroke care:

1. Individuals discharged home directly from the ED where the majority are considered TIA patients and at high risk for stroke require more consistent access to diagnostic imaging and dysphagia screening.

2. Patients in trajectories that include admission to hospital should have increased access to stroke units.

3. A large percentage of patients transitioning to LTC could potentially benefit from inpatient rehabilitation.

4. Discharge planning should include organization of timely follow-up with a physician familiar with secondary stroke prevention, particularly among patients discharged directly from the ED.

\section{ETHICS}

This study was approved by the Sunnybrook Health Sciences Centre Research Ethics Board.

\section{ACKNOWLEDGEMENTS}

We thank Jen Levi for her assistance with manuscript preparation. Parts of this material were based on data and information compiled and provided by the Canadian Institute for Health Information (CIHI). However, the analyses, conclusions, opinions and statements expressed herein are those of the author, and not necessarily those of the CIHI. The Ontario Stroke Registry is funded by the CSN and the Ontario Ministry of Health and LongTerm Care (MOHLTC). The ICES is supported by an operating grant from the MOHLTC. The opinions, results and conclusions are those of the authors and should not be attributed to any supporting or sponsoring agencies. No endorsement by the CSN, the ICES nor the MOHLTC is intended or should be inferred. We would also like to acknowledge support from the Health System Performance Research Network (grant no. 06034), supported by a grant from the MOHLTC.

\section{Disclosures}

Prosanta Mondal reports grants from the ICES and was supported by an operating grant from the MOHLTC during the conduct of this study.

Walter Wodchis has the following disclosure: University of Toronto, principal investigator; MOHLTC grant no. 06034.

Ruth Hall has the following disclosures: OSR (funded by the CSN and MOHLTC): evaluation specialist, salary; ICES, which is supported by an operating grant from the MOHLTC: adjunct scientist.

Jiming Fang has the following disclosure: ICES, which is supported by an operating grant from the MOHLTC: employee, salary.

Diana Sondergaard and Mark Bayley hereby state that they have nothing to disclose.

\section{SupPlementary Material}

To view supplementary material for this article (Appendix 1), please visit https://doi.org/10.1017/cjn.2016.440

\section{REFERENCES}

1. Stroke Unit Trialists' Collaboration. Organised inpatient (stroke unit) care for stroke. Cochrane Database of Syst Rev. 2007:(4): CD000197. Available at: http://onlinelibrary.wiley.com/doi/ 10.1002/14651858.CD000197.pub3/full.

2. Gassaway J, Horn SD, DeJong G, Smout RJ, Clark C, James R. Applying the clinical practice improvement approach to stroke rehabilitation: methods used and baseline results. Arch Phys Med Rehabil. 2005;86(12 Suppl 2):S16-33; Available at: http://www. archives-pmr.org/article/S0003-9993(05)01147-0/pdf.

3. Carinci F, Roti L, Francesconi P, Gini R, Tediosi F, Di Iorio T, et al. The impact of different rehabilitation strategies after major events in the elderly: the case of stroke and hip fracture in the Tuscany. BMC Health Serv Res. 2007;7:95. Available at: https:// www.ncbi.nlm.nih.gov/pmc/articles/PMC1939994/pdf/1472-69637-95.pdf.

4. Cloutier-Fisher DS. Different strokes: need for help among strokeaffected persons in British Columbia. Can J Public Health. 2005;96(3):221-5.

5. Foley N, Salter K, Teasell R. Specialized stroke services: a metaanalysis comparing three models of care. Cerebrovasc Dis. 2007;23(2-3):194-202. Epub ahead of print Dec 1, 2006.

6. Nguyen TA, Page A, Aggarwal A, Henke P. Social determinants of discharge destination for patients after stroke with low admission FIM instrument scores. Arch Phys Med Rehabil. 2007;88(6):740-744. 
Available at: http://www.archives-pmr.org/article/S0003-9993(07) 00220-1/pdf.

7. Ostwald SK, Davis S, Hersch G, Kelley C, Godwin KM. Evidencebased educational guidelines for stroke survivors after discharge home. J Neurosci Nurs. 2008;40(3):173-9; 191. Available at: https://www.ncbi.nlm.nih.gov/pmc/articles/PMC 2743441/pdf/nihms-107369.pdf.

8. Gregory PC, Han E. Disparities in post-acute stroke rehabilitation disposition to acute inpatient rehabilitation vs. home: findings from the North Carolina Hospital Discharge Database. Am J Phys Med Rehabil. 2009;88(2):100-7.

9. Teasell R, Meyer MJ, McClure A, Pan C, Murie-Fernandez M, Foley N, et al. Stroke rehabilitation: an international perspective. Top Stroke Rehabil. 2009;16(1):44-56.

10. Teasell R, Meyer MJ, Foley N, Salter K, Willems D. Stroke rehabilitation in Canada: a work in progress. Top Stroke Rehabil. 2009;16(1):11-9.

11. Vincent C, Robichaud VC, Desrosiers L, Belleville S, Demers L, Viscogliosi C, et al. Provision of rehabilitation services in Québec following stroke: a comparative survey conducted by postal questionnaire. Can J Aging. 2010;29(2):193-203. Epub ahead of print May 14.

12. Smith E, Hassan K, Fang J, Selchen D, Kapral M, Saposnik G. Do all ischemic stroke subtypes benefit from organized inpatient stroke care? Neurology. 2010;75(5):456-62; Epub ahead of print Jun 30. Available at: https://www.ncbi.nlm.nih.gov/pmc/articles/ PMC2918471/pdf/7888.pdf.

13. Coleman EA, Boult C. Improving the quality of transitional care for persons with complex care needs. J Am Geriatr Soc. 2003; 51(4):556-7.

14. Reker DM, Reid K, Duncan PW, Marshall C, Cowper D, Stansbury $\mathrm{J}$, et al. Development of an integrated stroke outcomes database within the Veterans Health Administration. J Rehabil Res Dev. 2005;42(1):77-91. Available at: http://www.rehab.research.va. gov/jour/05/42/1/Reker.html.

15. Jia H, Zheng Y, Reker DM, Cowper DC, Wu SS, Vogel WB, Young GC, et al. Multiple system utilization and mortality for veterans with stroke. Stroke. 2007;38(2):355-60. Available at: http:// stroke.ahajournals.org/content/38/2/355.long.

16. Coutts SB, Wein TH, Lindsay MP, Buck B, Cote R, Ellis P, et al. Canadian Stroke Best Practice Recommendations: secondary prevention of stroke guidelines, update 2014. Int J Stroke. 2015;10(3):282-91; Epub ahead of print Dec 23, 2014. Available at: http://journals.sagepub.com/doi/abs/10.1111/ijs.12439?url_ ver $=Z 39.88-2003 \& r f r \_i d=$ ori:rid:crossref.org\&rfr_dat=cr_pub $\overline{\%}$ 3dpubmed.

17. Kolominsky-Rabas PL, Sarti C, Heuschmann PU, Graf C, Siemonsen S, Neundoerfer B, et al. A prospective communitybased study of stroke in Germany: the Erlangen Stroke Project (ESPro): incidence and case fatality at 1, 3, and 12 months. Stroke. 1998;29(12):2501-6. Available at: http://stroke.aha journals.org/content/29/12/2501.long.
18. Thrift AG, Dewey HM, Macdonell RAL, McNeil JJ, Donnan GA. Stroke incidence on the East Coast of Australia: the North East Melbourne Stroke Incidence Study (NEMESIS). Stroke. 2000; 31(9):2087-92. Available at: http://stroke.ahajournals.org/ content/31/9/2087.long.

19. Hedworth AB, Smith CS. The Great Lakes Regional Stroke Network experience. Prev Chronic Dis. 2006;3(4):A128. Epub ahead of print Sep 15. Available at: https://www.ncbi.nlm.nih.gov/pmc/ articles/PMC1779291/pdf/PCD34A128.pdf.

20. Wenger NS, Young RT. Quality indicators for continuity and coordination of care in vulnerable elders. J Am Geriatr Soc. 2007; 55(Suppl 2):S285-92.

21. Hall R, Khan F, O'Callaghan C, Cullen A, Levi J, Wu J, et al. Ontario Stroke Evaluation Report 2014: On Target for Stroke Prevention and Care. Toronto: Institute for Clinical Evaluative Sciences; 2014. Available at: http://www.ices.on.ca/ /media/Files/AtlasesReports/2014/Stroke-Evaluation-Report/Full-Report.ashx.

22. Kapral MK, Silver FL, Richards JA, Lindsay MP, Fang J, Shi S, et al. Registry of the Canadian Stroke Network: Progress Report 2001-2005. Toronto: Institute for Clinical Evaluative Sciences; 2005. Available at: http://www.ices.on.ca/ /media/Files/Atlases-Reports/ 2005/RCSN-progress-report-2001-2005/Full\%20report.ashx.

23. Hall R, Khan F, O'Callaghan C, Cullen A, Levi J, Wu J, et al. Ontario Stroke Evaluation Report 2014: On Target for Stroke Prevention and Care. Supplement: Ontario Stroke Report Cards. Toronto: Institute for Clinical Evaluative Sciences; 2014. Available at: http://www.ices.on.ca/ /media/Files/Atlases-Reports/2014/ Stroke-Evaluation-Report/Full-Report.ashx.

24. Saposnik G, Fang J, O’Donnell M, Hachinski V, Kapral MK, Hill MD. Escalating levels of access to in-hospital care and stroke mortality. Stroke. 2008;39(9):2522-30. Epub ahead of print Jul 10. Available at: http://stroke.ahajournals.org/content/39/9/2522.long.

25. Bejot Y, Rouaud O, Jacquin A, Osseby GV, Durier J, Manckoundia P, et al. Stroke in the very old: incidence, risk factors, clinical features, outcomes and access to resources: a 22-year population-based study. Cerebrovasc Dis. 2010;29:111-21. Epub ahead of print Dec 1, 2009.

26. Tung JM, Mamdani MM, Juurlink DN, Paterson JM, Kapral MK, Gomes T. Rates of ischemic stroke during warfarin treatment for atrial fibrillation. Stroke. 2015;46(4):1120-2. Epub ahead of print Feb 19. Available at: http://stroke.ahajournals.org/content/46/4/ 1120.long.

27. Saposnik G, Kapral M, Coutts S, Fang J, Demchuk A, Hill M. Do all age groups benefit from organized inpatient stroke care? Stroke. 2009;40(10):3321-7; Epub ahead of print Jul 30. Available at: http://stroke.ahajournals.org/content/40/10/3321.long.

28. Hall R, Khan F, Levi J, Zhou L, Lumsden J, Martin C, Morrison K, et al. Ontario and LHIN 2014/15 Stroke Report Cards and Progress Reports: Active Knowledge Exchange to Drive System Integration and Stroke Best Practices. Toronto: Institute for Clinical Evaluative Sciences; 2016. Available at: http://www.ices. on.ca/ /media/Files/Atlases-Reports/2016/Ontario-Stroke-Report2016/ICES_Stroke_Report_2016.ashx. 